\title{
Verification of Material Composition and Manufacturing Process of Carbon Fibre Wheel
}

Lukáš Maňas $^{1,2}$, Soňa Rusnáková ${ }^{1}$, Jakub Javořík ${ }^{1}$, Milan Žaludek ${ }^{1}$, Ladislav Fojt1 ${ }^{1,2}$

${ }^{1}$ Department of Production Engineering, Faculty of Technology, Tomas Bata University in Zlín. Vavrečkova 275, 76001 Zlín.Czech Republic.E-mail:1manas@utb.cz, rusnakova@utb.cz,javorik@utb.cz, zaludek@utb.cz, fojtl@utb.cz, ${ }^{2}$ Centre of Polymer Systems, Tomas Bata University in Zlín, tř.Tomáše Bati 5678, 76001 Zlín. Czech Republic.

Presented research paper is focused on the development of carbon fibre wheel. Considering development and construction of wheels for the automotive and motorcycle industry, low weight is one of the most significant factors. In the case of rotating components, the imbalance of the assembly is a problem. This fact affects handling of the vehicle or wheel behavior under the load, for example in the point of turning, acceleration or drive on damaged road. Determination of the most appropriate material composition (sequence) is primarily the main problem of composite material application. Correct design of material composition and also lay-up diagram is determined by material characteristics and strength requirements. A suitable solution is in the application of a group of input material structures creating hybrid composite. Specific combination of various input materials (aluminum ring, 3D printed plastic honeycomb core and carbon fibre composites) guarantees and ensures the fulfilment of the strength requirements which are determined during each particular application. The main aim of presented paper was to design material composition and shape of carbon fibre wheel that were subsequently verified by successful manufacturing process.

Keywords: Composite Material, Carbon Fibre, Hybrid Core, Prepreg, Wheel

\section{Introduction}

Carbon fibre composite materials penetrate into all sectors of industry and find their place in aerospace, automotive or sports industry as well. In the case of composite discs that can be located to automotive or sport industry, there are high requirements on their construction and the same are applied to support materials. Production of complicated composite structures is possible with using miscellaneous technologies, but also by different support materials. Types and technological solutions of the supporting materials affect the resulting final components $[1$, 2].

For the production of composite discs, compression molding technology is used. In case of two or more side molds, there is no problem to create a product that consists entirely of facing surfaces. This type of technology uses the supporting material inside the structure - special hybrid core. The form of the supporting materials can affect the rigidity of these structures. It may have either positive or negative effect on the resulting properties. In the case of negative properties, the rigidity of the whole assembly is reduced. Conversely, positive properties induce a better connection with the core material. This has a positive effect on the overall properties - better connection of materials in the whole [3-7].

The aim of the presented article is to design and experimentally verify compression molding technology used for the production of composition wheels made of carbon fibre preimpregnated materials that were subsequently verified by successful manufacturing process. The emphasis is placed on the material and technological solution of the core structure to manufacture even more quality products. The problem can be the connection formed between materials in the parting line of the mold, which can then weaken the whole disk structure [8].

\section{Experiment}

To verify the material composition of the structure and technological process of production, materials that guarantee the required properties throughout the proces have been selected. Used 3D disc model is based on the standard R13 magnesium disc. Its basic dimensions have been preserved. This makes it possible to use the original fastening system with a central nut and pins. This is a standart mounting of these discs. The Catia V5 software was used for construction of the mold. The design was based on the basic dimensions of the original magnesium disc and the input parameters for the NX 11 software that seved for machining programming. The triangular type of the CTRIA3 elements with a edge size of $5 \mathrm{~mm}$ were selected for disk analysis using Finite Element Method (FEM). For the first analysis, the isotropic structure, represented by duraluminum materiál was chosen. Boundary conditions have been defined based on disc fixture and its shape, loads were applied with respect to loadings measured on magnesium disc. The individual value of the load applied to the wheel model are the result of tensometric measurements that were conducted independently at the practice and are based on weight combination of car and expected driver weight. Input material data used for FEM analysis were selected from material library integrated into NX 11 software and correspond to those used for magnesium wheel production. The exact composition of magnesium is not available from the manufacturer; thus raw magnesium was chosen (with no additives). This method seems to be sufficient for initial simulations.

For the simulation, it was important to set the boundary conditions that imitate the real conditions of disk anchorage on the hub. In fact, the disk is mounted on the hub and the resulting torque is transmitted through the hub pins. To simplify the analysis, the disc was anchored by a solid bond between bearing surface of the carbon wheel and the axle hub. Finally, wheel was loaded with vertical force, corresponding to the force when passing through a curve road, equal to $4250 \mathrm{~N}$.

Several design solutions have been proposed and 
found solutions then revealed weak points through simple analyzes. Due to the isotropic structure, disc redesigns and detection of weaknesses were possible in a short time on several prepared design solutions. Attention has been paid to weak spots and these locations have been optimized in design of carbon disc. An example of the basic analysis can be seen in Fig 1. Right side of this figure depics stress values caused by force applied into the center of wheel bearing surface and shows critical areas in future composite disk structure.
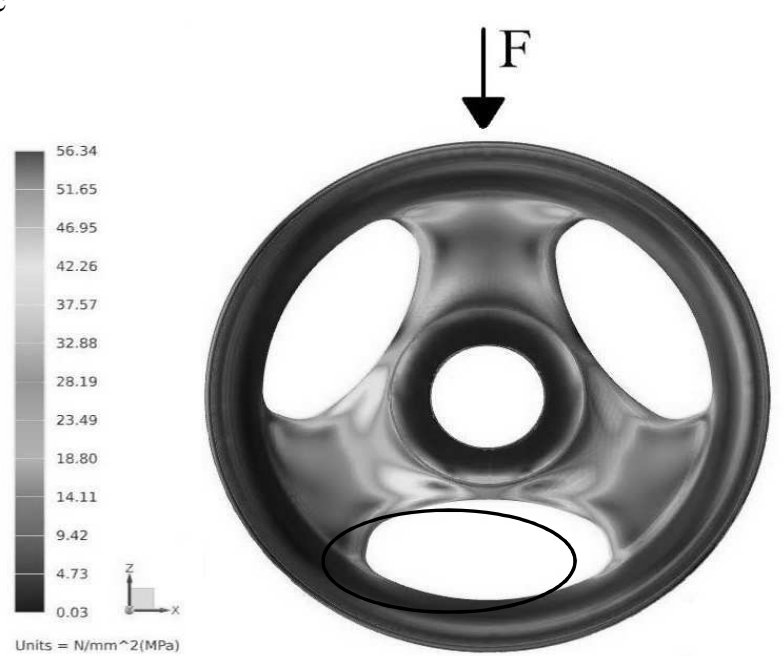

Fig. $13 D$ model of wheel disc (left) and resulting stresses of basic magnesium disc design (right)

After removing weaknesses and design optimalization, the final shape of 3D model was designed. The carbon pre-impregnated material has been assigned to the created mesh in FEM software. The material properties correspond to the used prepreg GG200T-DT120-42. It is a transversally isotropic material that has five independent constants. The honeycomb core insert inside the disc was made by $3 \mathrm{D}$ print and was connected to an aluminum alloy ring, which is an isotropic material having two independent constants.
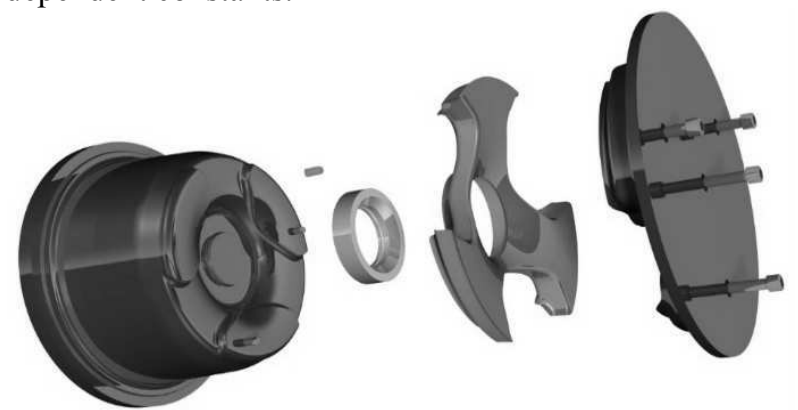

Fig. 2 Mold assembly with aluminium insert (yellow) and honeycomb $3 D$ printed core (green)

The carbon prepreg has been placed to each laminate layer separately to achieve individual angles of rotation between the fabric layers. For the analyzes, seven sizes of angles were used, under which individual layers of fabric were placed. After setting the boundary conditions and load forces, the assembly was analyzed and evaluated.

For manufacturing of the mold, aluminum material was chosen. Aluminium mold has a standard construction design, but allows to use the components with a different shell thickness to produce different discs. It is possible to change the size of the core. Selected aluminium material was easily formed into a required shape and much less production time was necessary for the mold production and necessary surface treatment. The Catia V5 software was used to design the mold (Fig. 2), and SolidCAM was used to simulate CNC machining and creation of G-code. The mold can be placed in a heated oven or autoclave. For study purposes, the mold can also be used in laboratory conditions, especially for teaching activities with prepreg materials due to complex shapes.

The aluminum material was also applied to produce a core insert ring. This insert allows disc to be mounted and attached to the axle hub. After demolding the finished disk, several holes were drilled into this insert. Four holes were used for the positioning of the wheel on the hub precisely and to capture the reaction during driving. The central nut was also utilize to position the disc accurately. The nut presses against a used aluminum insert. This does not deform the inner and outer shape structure of the disc when the tightening torque is reached.

The production of the hybrid core needed to form the inner support shell involved several steps. After defining the boundaries of the core, its shape was designed. Joining parts and all core segments followed. Segments were prepared using 3D printing technology. Each segment consists of a shell with a honeycomb core. The shell thickness of the core was $1 \mathrm{~mm}$ - sufficient to subsequently cure of the core in an assembly in a heated oven (without its deformation). Core segments were joined with an aluminum insert using a heat-resistant adhesive.

Carbon pre-impregnated material was applied to the prepared segments. This layers consisted of carbon fibers with areal weight of $200 \mathrm{~g} / \mathrm{m}^{2}$. Individual layers were placed on the core according to generally known rules used to lay-up of prepreg material. The number of layers and their placement fully corresponds to the analysis that involves the individual layers of material. In order to store individual layers, paper templates were created to ensure elimination of butt joints in same area, especially in areas of the highest loads. These areas were covered by prepreg 
material without any joints and fulfilment of strength requirement is thus expected. In practice, overlap of butt

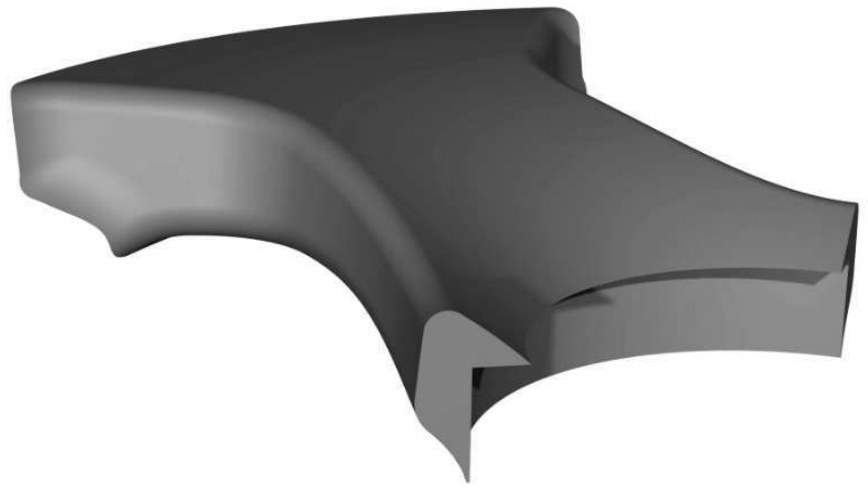

joints between individual layers is allowable, if overlapping of individual layers is at least $30 \mathrm{~mm}$.

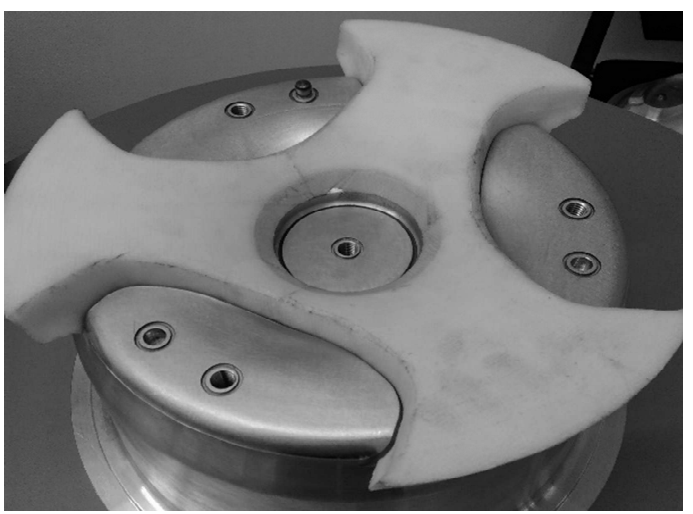

Fig. 3 Segment 3D model (left) and prepared reinforcing core (right)

Emphasis was placed on the uniform thickness of the resulting shell. Thus, the prepared core placed into a vacuum bag, inside air evacuated and whole unit was placed into a heated oven. The curing program was selected with respect to the applied core materials. A lower temperature was emploed for a longer period of time, namelly $80{ }^{\circ} \mathrm{C}$ for 12 hours. However, this material is possible to be reprocessed at higher temperatures, where it further affects the resulting properties of the structure (so called postcuring). Layers of carbon prepreg material were subsequently loaded into two-part mold that was separated by suitable release agent. In total, five layers of the same material were used as in the case of core insert production. A core (Fig. 3) was inserted between the mold halves and the mold was closed. Ten layers of carbon plain fabric of $200 \mathrm{~g} / \mathrm{m}^{2}$ areal weigh and two layers of special hybrid aramid plain fabric of areal weight of $225 \mathrm{~g} / \mathrm{m}^{2}$ were added around the disk circumference. Supporting materials, such as tearing and separation fabrics, were added and the entire assembly was inserted into the heated oven for 90 minutes at $120^{\circ} \mathrm{C}$ (this program was post-curing program for core insert in the disc. In all curing processes the structures were connected to a vacuum source.
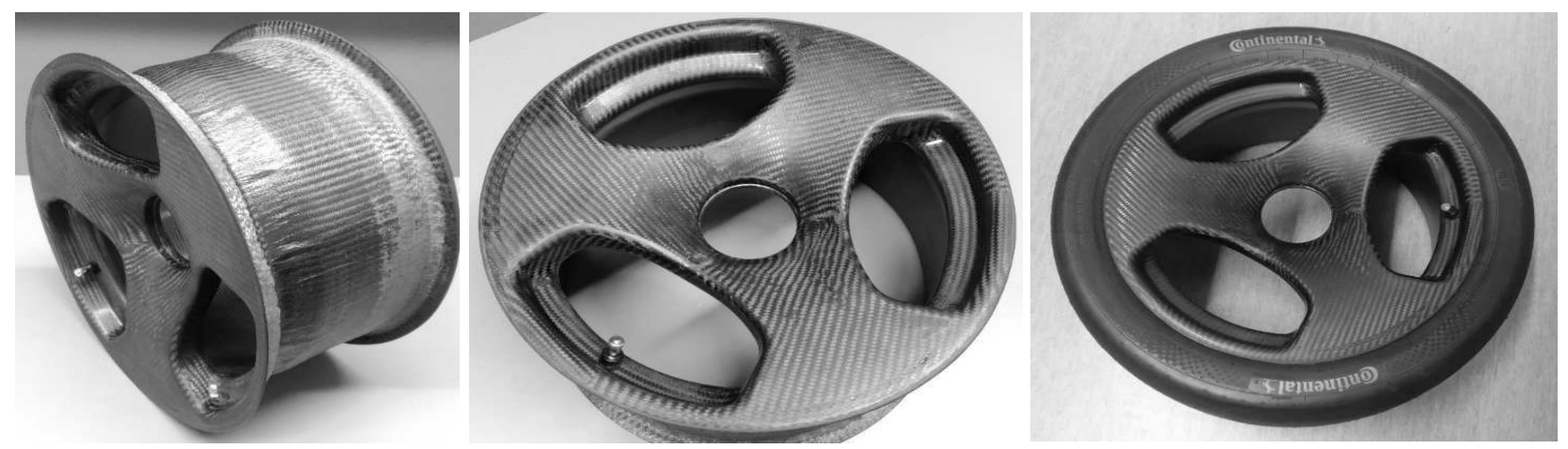

Fig. 4 Carbon wheel disc after demoulding (left) and finishing operations (right)

\section{Summary and discussion}

Compression molding technology is a standard technology used in the production of composite components. In this case, technology allows to produce parts with specified requirements - allfacing surface with a precisely constituted core. All technological requirements were transferred into the design of the production of a two-side mold with polished cavity shapes.

The first step was the production of the core necessary to meet the required conditions. The core consisted of honeycomb inner structure, aluminum insert ring and four layers of carbon fabric cover. Used honeycomb inner structure was manufactured using 3D printing that allows to produce spesfic shapes, and also enables shape changes of inner honeycomb structure itself (different honeycomb shapes and dimensions). Normally, construction 3D printed parts are produced from Acrylonitrile butadiene styrene (ABS) material that shows very good adhesion to thermoset matrix. This material is also capable to withstand a curing program for prepreg materials.

Individual layers of prepreg materials and separately manufactured core covered by pre-cured carbon prepred were inserted into the prepared mold. Pre-cured hybrid core had coarse surface due to use and subsequent removal of peel ply. This surface helped to create better connection between core and layers of facing carbon fabric. The advantages of this individual parts lay-up is the full connection between the core and carbon fibre layers.

The use of hybrid supporting core can replace simple butt joint in this two side mold by perfect areal connection provided by whole hybrid core surface. This connection is specific by higher resistance without failures under loading. The result is a carbon disc formed with an inner shell. On the other hand, there is main problem in the production of hollow composite parts - connection between individual layers mold parting line. This is main problem 
in production with complex segment molds, where inner blowing membrane is not possible to be used.

These findings may be applied in the production of hollow components, where inner vaccum bag is not possible to use due to mold complexity. If the core is used as a mold part, it becomes a permanent part of the resulting product. In practice, this means producing a hollow part in two steps. In the first step, a sufficiently stiff and strong core is formed from the same material as the material inserted into the manufacturing mold. Number of layers used for core production depends on requested mechanical properties and have to be chosen with respect to fact that it can not be deformed during mold closing.

Several types of semi-finished products can be used for different supporting core shapes and types. It is possible to change the production technology and manufacture cores separately in production molds, namely foam supporting structures with defined shape. This core material change can bring better properties of resulting structure without a need of mold design and dimension changes additional mold cavity adjustments. Additional weight reduction can be achieved by removal of supporting inner structure (3D honeycomb) from prepared shell structure (by use of wax material or materials that are soluable in water). This modification is particularly advantageous for rotary components. However, in case of tubular profile production, its better to use reinforcing material in form of stockinette that creates final product without material folds and butt joints.

During individual layers lay-up, it was necessary to pay attention to the overlapping and precise positioning of individual paper templates of the material. It was particularly undesirable to group butt joints of the individual layers deposited into the same place, thereby weakening the whole structure. With the help of the previous FEM analyzes, the layer connections were placed outside the critical locations given by the software.

In the experiment, carbon fibre composite disc was manufactured that coresponds by its design (basic dimensions and shape) to standard magnesium disc with weight of $2400 \mathrm{~g}$. Manufactured disc represents a weight saving of $315 \mathrm{~g}$, having final weight of $2085 \mathrm{~g}$. The effect of weight savings and overall composite disk properties will be further verified in a dynamic radial fatigue test based on SAE J267 standard in cooperative testing institute.

The next step in the experiment focused on composite disc is performing dynamic testing according to standard SAE J267 Chapter 4, Dynamic Radial Fatigue Test, Disk Wheels, and Demoutable Rims, where also the effect of weight savings and overall composite disk properties will be further verified. The test procedure consists in selecting a test tire according to the approved type and size for the prepared composite disc. For the manufactured disk, the tire size is equal to 205/470R13 approved in Formula Student rules (Fig. 4). The disc is clamped using an approved adapter and nut. During this test is inflated to
$448 \mathrm{kPa} \pm 14 \mathrm{kPa}$ and fastening nut is tightened by defined torque. During this test, a pressure inside the tire may slightly rise, where this fact is connected to applied stress. The radial load is set to $1180 \mathrm{~N}$ and is based on the tire manufacturer's recommended values. To meet the test conditions, the minimum life cycle of 500,000 cycles is given by the mentioned standard. Results obtained from this experiment will be used for further comparison with FEM analysis results [9].

\section{Acknowledgement}

This work was supported by the internal grant of TBU in Zlín No. IGA/FT/2018/004 funded from the resources of specific university research.

\section{References}

[1] NOAKES, K. (2008). Successful composite techniques: a practical introduction to the use of modern composite materials. p. 144. The Crowood Press, Ramsbury.

[2] WANBERG, J. (2014) Composite materials: step by step projects. p.144. MN: Wolfgang Publications, Stillwater.

[3] ŽMINDÁK, M., PELAGIĆ, Z., SOUKUP, J. (2015) Analysis of Fiber Orientation Influence to Dynamic Properties of Composite Structures. In: Manufacturing Technology, Vol. 15, Issue 3, pp. 490-494, ISSN 1213-2489.

[4] MÜller, M., RUGGIERO, A., VALÁŠEK, P. (2017) Mechanical Characterisation of Metal/Polymeric Composite Waste/Metal Sandwich Panel. In: Manufacturing Technology, Vol. 17, Issue 4, pp. 530-536, ISSN 1213-2489.

[5] WEN, M., LUO, J. (2015). Study on Mechanical Properties of the Composite Resin Matrix Fiber Reinforced. In: Manufacturing Technology, Vol. 15, Issue 2, pp. 243-249, ISSN 1213-2489.

[6] SMETANKA, L., GERLICI, J., LACK, T., PELAGIĆ, Z. (2014). Homogenization of Fibers Reinforced Composite Materials for Simulation Analysis. In: Manufacturing Technology, Vol. 15, Issue 5, pp. 914-920, ISSN 1213-2489.

[7] KULHAVÝ, P., LEPSIK, P. (2017). Digitization of Structured Composite Plates with Regard to Their Numerical Simulations. In: Manufacturing Technology, Vol. 17, Issue 2, pp. 197-203, ISSN 1213-2489.

[8] KR101394875. Process for an Assembly Type Carbon Fiber Composite Wheel and an Assembly Type Carbon Fiber Composite Wheel Thereby. Patent. 2014.

[9] SAE J267. Wheel/Rims - Trucks - Performance Requirements and Test Procedures. SAE standard. 1999. 